\title{
Expectativa de futuro e juventudes: a escolha profissional dos jovens nas reportagens da imprensa (Brasil, 1980-2000)
}

\author{
Luciana Rossato*
}

Iucianarossato1972@gmail.com

Nathália Jonaine Hermann**

nathaliahermann@gmail.com

\begin{abstract}
Resumo
Este artigo tem o objetivo de analisar como os jovens e suas escolhas profissionais para o futuro são apresentadas na imprensa brasileira. Para isso, serão analisados, dentre peças publicitárias, reportagens e entrevistas, documentos que tenham como tema específico o vestibular, publicados nas revistas IstoÉ e Veja entre o começo da década de 1980 e o final da década de 1990. Busca-se, com a pesquisa, identificar que imagem de juventude então se construiu, tendo como parâmetro a estreita relação da preocupação com o futuro a partir de um conjunto de reportagens cujo tema eram a escolha profissional e a aprovação no vestibular. Para esta análise, recorremos, aos conceitos de juventudes: a Margulis e Urresti (1996) e de Leccardi (2005); de expectativa de futuro, a de Koselleck (2006; 2014); de representação, a Chartier (1991; 2011) e de imprensa, a de Luca (2006) e Abreu (2002).
\end{abstract}

\section{Palavras-chave}

Juventudes; Futuro; Imprensa

\section{Future expectations and youth: the professionals choice of the young people in press reports (Brazil, 1980-2000)}

\begin{abstract}
This article has the objective of analyzing how young people and their future professional choices are presented in the Brazilian press. For this purpose, documents will be analyzed - amongst them will be advertisements, reports and interviews - that contain the college exam as a theme and that were published in the magazines IstoE and Veja from the beginning of 1980 to the end of 1990. This research has the purpose of identifying how an image was constructed of a youth that was preoccupied about the future, from several reports that had the college exam and professional choice as their main theme. For this analyses we utilized the concepts of youth from Margulis and Urrestis (1996) and from Leccardi (2005), the concept of future expectation from Koselleck (2006; 2014), the concept of representation from Chartier $(1991 ; 2011)$ and the concept of press from De Luca (2006) and Abreu (2002).
\end{abstract}

\section{Keywords}

Youth; Future; Press

\footnotetext{
*Professora do Departamento de História e do Programa de Pós-graduação em História e do Mestrado Profissional em Ensino de História da Universidade do Estado de Santa Catarina (UDESC).

**Mestranda no Programa de Pós-Graduação em História da Universidade do Estado de Santa Catarina (UDESC). Bolsista do Programa de Bolsas de Monitoria de Pós-Graduação (PROMOP/UDESC).
} 
$\mathrm{O}$ ensino superior era um problema que permeava o sistema educacional brasileiro, uma vez que o ingresso da juventude em universidades era marcado por uma série de dificuldades. O jovem que prestava vestibular era descrito como "produto de um sistema fragmentário de ensino, $[\ldots]$ que arrasta até o funil catastrófico do vestibular deficiências de seus primeiros dias de aula" (Veja, 4 fev. 1987, p. 39), segundo a reportagem "Falta de fôlego", da revista Veja (4 fev. 1987, p. 39).

O futuro dos jovens é uma preocupação presente em diferentes contextos históricos. No Brasil, o governo militar, após tramitação sumária no Congresso, sancionou a Lei 5.692/1971, que instituiu o ensino médio de $1^{\mathrm{o}}$ e $2^{\mathrm{o}}$ grau. ${ }^{1}$ Esta lei tornou compulsória a formação profissional no $2^{\circ}$ grau $^{2}$. Em decorrência disso, esses currículos foram modificados e tiveram sua formação geral, principalmente a de humanas, diminuída ou mesmo eliminada. Em 1982, o MEC aprovou a Lei 7.044, alterando alguns dos dispositivos da reforma de 1971. Esta, juntamente com a reforma universitária, foi uma tentativa dos governos militares de implementar um projeto que tinha como objetivo estabelecer uma determinada formação para os jovens brasileiros. O objetivo era que o ensino de $2^{\circ}$ grau possuísse uma terminalidade, de modo que os jovens, ao final do curso, tivessem uma profissão, abolindo, dessa forma, o ensino propedêutico cujo objetivo era a preparação para o vestibular e a entrada no ensino superior. Até 1971, todos os que passavam no vestibular tinham direito a vaga nas universidades públicas, o que mudou com a instituição do vestibular classificatório nesse ano.
No início da década de 1970, o país estava passando por uma fase de crescimento econômico, o que demandava mão de obra qualificada. Outro fator que vai afetar a demanda por educação é o grande crescimento da população urbana, em decorrência da migração do campo para a cidade. Nas décadas de 1960 e 1970, principalmente nas Regiões Sul e Sudeste, a taxa de crescimento urbano das capitais girava em torno de 6\% ao ano. Aproximadamente 27 milhões de pessoas migraram do campo para a cidade. Segundo Klein e Luna (2014, p. 43-44), “até 1960, a maioria da população morava no campo. Mas, em 1970, mais da metade da população foi recenseada como urbana, e esse índice cresceu de forma constante, até atingir $80 \%$ da população nacional no censo de 2000”.

Com o crescimento das cidades e da economia, houve também uma demanda maior por formação escolar, pressionando os governos por soluções para problemas como o analfabetismo, a qualidade da educação oferecida às crianças e aos jovens, a baixa formação dos trabalhadores, além do aumento do número de jovens que tentavam vaga nas universidades públicas e/ ou privadas. Essa preocupação não se restringiu aos órgãos públicos. Pautava-se também pela imprensa nacional, e aparecia em reportagens nas revistas Veja, IstoÉ, e nos jornais Folha de S. Paulo, O Globo, Zero Hora, O Estado. São frequentes temas como o vestibular e a qualidade ou não da educação das crianças e jovens, constituindo assunto de reportagens (muitas vezes de capa), entrevistas ou propagandas na imprensa nacional ou local. ${ }^{3}$

${ }^{1}$ Em 11 de agosto de 1971 foi instituída as Diretrizes e Bases para o ensino de $1^{\circ}$ e $2^{\circ}$ graus. http://www2.camara.leg.br/legin/fed/lei/1970-1979/lei-569211-agosto-1971-357752-publicacaooriginal-1-pl.html

${ }^{2}$ Com LEI No 9.394 de 20 de dezembro de 1996 foram estabelecidos as Diretrizes e Bases da Educação Nacional e a denominação foi mudada de $1^{\text {a }}$ e $2^{\text {a }}$ Graus para Ensino Infantil, Fundamental e Médio. http://portal.mec.gov.br/seesp/arquivos/pdf/lei9394 ldbn1.pdf

${ }^{3}$ Sobre isto ver: ROSSATO, Luciana. As escolas brasileiras de educação básica nas revistas Veja, Visão e IstoÉ (1980-1989). In: LOHN, Reinaldo Lindolfo. (Org.). História nas bancas de revistas: um país impresso: entre representações sociais e culturas políticas. Ponta Grossa: TodaPalavra, 2016. p. 191-211. 
Os documentos que analisaremos neste artigo são entendidos como artefatos culturais; além de informar e noticiar, desempenham outros papéis, como o de entreter e educar. A imprensa apresenta dados, notícias, discussões, opiniões, fatos e acontecimentos; divulga mensagens e constrói significados. As narrativas que os impressos elaboram sobre determinados temas e grupos contribuem para formar representações e produzir práticas (CHARTIER, 1991, 2011). As revistas semanais, da mesma forma que outros veículos de comunicação, escolhem, entre as inúmeras coisas que acontecem, o que será veiculado e, assim, se tornará um acontecimento. O que e como é noticiado não é o acontecido, mas o que, através das mídia, passa a ser visto como tal. Como defende Chartier (2011, p. 16) "não existe história possível se não se articulam as representações das práticas e as práticas das representações".

\section{O papel da imprensa}

No Brasil, a publicação de revistas ocorre desde o século XIX, a partir de modelos importados de Portugal. Nas décadas de 1930 a 1950, a revista de maior tiragem era a Cruzeiro, que, em 1947, chegou a alcançar $37,7 \%$ dos leitores desse tipo de periódico (RIBEIRO, 2006). A revista era voltada a um público amplo, não segmentado por idade ou gênero; caracterizava-se por um modelo de fotojornalismo no qual o texto escrito não passava de coadjuvante das imagens. Esse modelo, a partir da segunda metade da década de 1960, ganha outra forma. Essa década é marcada por grandes mudanças no parque gráfico brasileiro, com a modernização do sistema gráfico e da diagramação, pela extinção de inúmeros títulos de jornais e o fortale- cimento de outros que passaram a se basear "nas normas técnicas do modelo norte-americano, centrado nos ideais de objetividade, neutralidade e imparcialidade" (RIBEIRO, 2006, p. 430).

A modernização da imprensa, durante os governos militares, esteve relacionada com os avanços tecnológicos na área da informática, do registro de imagens e de audiovisual. De acordo com Abreu (2002), o alto investimento em tais tecnologias iria, posteriormente, baratear os custos de produção. A historiadora Maria Celeste Mira (1997) analisa esse fato, tratando especificamente da Editora Abril, como processo de modernização da indústria de comunicação. De acordo com a autora, o mais importante não era entender se a editora havia recebido um investimento internacional ou apenas nacional, mas como este projeto audacioso a conectava com a "mundialização da cultura", termo utilizado por Renato Ortiz (1994). Segundo Mira, a editora desempenharia "um importante papel, sendo a responsável pela adaptação de quase todos os modelos e fórmulas editoriais mundializados em circulação no Brasil” (MIRA, 1997, p.13).

Nessa época, também ocorreram mudanças na produção de notícias, posto que o leitor passou a ser o produto da revista, o que, por consequência, levou à criação de "uma relação estreita entre as exigências mercadológicas e as redações" (ABREU, 2002, p. 29). Nos anos 1970, surgiram os cadernos específicos, como os de saúde, futebol, economia e educação, entre outros, com a finalidade de atingir diferentes públicos ${ }^{4}$. Tornam-se constantes as matérias, e até mesmo cadernos especiais, sobre eventos ou instituições com o objetivo de atrair publicidade para as revistas. As notícias

${ }^{4}$ É importante ressaltar que os "diferentes públicos" estavam dentro da lógica da classe média burguesa e também no âmbito da chamada família tradicional. Ver sobre em: MIRA, Maria Celeste. O leitor e a banca de revistas: o caso da editora Abril. Tese (Doutorado em Sociologia), Campinas, Universidade Estadual de Campinas, 1997. 
alternam-se, de grandes reportagens a textos mais curtos, a títulos sintéticos e chamativos. Além da utilização de imagens, as revistas passam a utilizar com mais frequência recursos gráficos, como tabelas, quadros e mapas. Nesse período, também se adota um padrão textual "impessoal, seco, descritivo e rigoroso", evitando expressar juízos de valor. Nos artigos e colunas, permitiam-se comentários pessoais (ABREU, 2002). Outro aspecto que gerou mudanças na produção das notícias foi a compartimentação do trabalho nas redações. A notícia, antes de ser publicada, passava por tantas mãos que, muitas vezes e ao final de uma reportagem, não se sabia quem fosse o autor, tamanha era a sua objetividade. Segundo Abreu, entre os profissionais da imprensa, especialmente da escrita, começava a prevalecer o conceito de "utilidade social" da mídia, ou seja, de que a atividade jornalística devia servir a interesses concretos dos cidadãos e responder a preocupações dos leitores ou da audiência - "o jornalismo-cidadão" (2002, p. 45). Muitas dessas mudanças decorriam de transformações operadas em outros setores, como a criação dos primeiros cursos de jornalismo em São Paulo e Rio de Janeiro, sem contar a criação do Ministério da Comunicação em 1967, de uma política nacional de comunicação.

As revistas e os jornais, como parte da mídia impressa, eram resultado de representações contextualizadas da realidade que acabavam trazendo à tona a perspectiva de um grupo seleto, embora difundido como preocupação coletiva. Segundo a historiadora Maria Helena Capelato, "nos vários tipos de periódicos [...] encontramos projetos políticos e visões de mundo representativas de vários setores da sociedade" (CAPELATO, 1988, p. 34). Na perspectiva de Francismar Carvalho, corroborando a afirmativa anterior, as representações variavam "segundo as disposições dos grupos ou classes sociais; aspiram à universalidade, mas são sempre determinadas pelos interesses dos grupos que as forjam" (CARVALHO, 2005, p. 49). Ou seja, nos casos em que a mídia impressa é fonte de pesquisa de historiadores e historiadoras, é essencial levar em conta que a imprensa não passa de um conjunto de representações da realidade de determinado período e, na maioria das vezes, defende interesses particulares.

Para Silva (2014), os meios de comunicação são determinantes nas sociedades contemporâneas para a construção de uma ideia de história ou de uma memória pública. As narrativas jornalísticas são as protagonistas desse processo, pois selecionam, entre os fatos ocorridos, o que deve ser lembrado no futuro. Um desafio metodológico sobre como utilizar as fontes jornalísticas para a análise histórica é não buscar nelas a confirmação de uma ideia, ou dos eventos registrados. Com esta pesquisa, busca-se identificar como foi construída a imagem da juventude de determinada época, relacionando-a estreitamente com a preocupação relativamente ao futuro a partir de um conjunto de reportagens cujos temas principais eram a escolha profissional e a aprovação no vestibular. Ao longo da leitura das reportagens que têm o vestibular e os jovens como foco, é possível identificar as perspectivas de futuro e de juventude então veiculadas nessas revistas.

Optamos por analisar documentos veiculados em dois órgãos da imprensa nacional: as revistas Veja e IstoÉ. A revista Veja é a principal publicação da Editora Abril. Começou a circular no ano de 1968; no decorrer das décadas de 1970 e 1980, tornou-se a revista semanal de maior circulação no país. Autodenominandose "indispensável", tinha como público alvo homens e mulheres adultos das classes A e B. Seu principal objetivo era informar o leitor das principais notícias do mundo - política, esporte, cultura, economia - e, em curto período de tempo, situar o seu público consumidor na lógica global, segundo a qual era preciso economizar tempo e manter-se informado. O número de páginas de cada edição da revista variava de 90 a 120. Era 
dividida por seções, com diversos temas: economia, saúde, política, cultura, história, educação, entre outros. Cada uma delas estava voltada a um público específico. A priori, política e economia, era voltado ao pai de família, ao empresário, ao homem de negócios. A parte de saúde e educação era geralmente voltada ao público feminino. Cultura, esportes e história voltavam-se a ambos os públicos, porém, mais jovens. Além disso, a análise sobre a seção de história mostrará como a revista utilizou exemplos do passado para criar uma narrativa a ser utilizada no presente.

A revista Istó́ começou a circular no ano de 1976. Em seu primeiro ano, apareceu como uma revista mensal. A partir de março de 1977, passou a ter circulação semanal, o que ocorreu devido ao êxito editorial que a levou, segundo Mino Carta, a participar ativamente no debate sobre os problemas nacionais. Publicada pela Editora Três, tinha como editor o próprio jornalista (que tinha trabalhado como editor da revista Veja). Diferente das demais revistas analisadas, a IstoÉ trazia a autoria dos artigos publicados, com o intuito de identificar o jornalista ou o colaborador que redigira o texto. Segundo Juliana Miranda (2014), a revista "tendia a ir além das críticas, propondo, em suas matérias, reflexões históricas e sociológicas mais profundas " (2014, p. 37). Além do maior tempo dedicado à elaboração das notícias em comparação ao de um jornal ou semanário, a IstoÉ contava com a contribuição de especialistas em ciências humanas que atuavam como colunistas mensais ou convidados.

O Instituto Verificador de Comunicação(IVC) dispõe de dados sobre a circulação das duas revistas na década de $1980^{5}$. A Veja duplicou sua circulação no decorrer da década de 1980. No primeiro trimestre daquele ano, pôs em circulação um total de 327.133 exemplares. No final da década, no $4^{\circ}$ trimestre de 1989, o total de exemplares subiu para 765.715.

Os dados referentes à IstoÉ são incompletos. No $2^{\circ}$ trimestre de 1982 , foram vendidos 112.737 exemplares. Os últimos dados da década são do $4^{\circ}$ trimestre de 1987, quando circularam 157.698 exemplares. Para efeitos de comparação, nesse mesmo trimestre foram postos em circulação 753.725 exemplares da revista Veja. Os dados do IVC só mostram o número de revistas que circularam. Não é possível identificar quais as regiões e/ou estados onde eram mais lidas.

\section{O vestibular, o mercado de trabalho e as expectativas de futuro da juventude}

O recorte selecionado, que abrange desde a década de 1980 até a década 1990, traz à tona uma juventude marcada por uma série de eventos externos que impactaram em suas escolhas profissionais. O caráter transicional garante à juventude a ideia de uma fase da vida que carrega consigo uma série de mudanças e inquietudes, justamente porque é nela que os indivíduos desenvolvem suas maturidades intelectuais e sexuais, assim como o pleno florescimento de suas faculdades mentais (LEVI; SCHMITT, 1996, p. 8). A própria noção de transição, que acompanha a faixa etária, também se aproximava do contexto transitório brasileiro, que passou pelo fim de uma ditadura militar dentro do recorte da pesquisa.

Tomando o ano de 1985 como exemplo, proclamado pela ONU como o ano mundial da juventude, percebia-se como esta era significativa tanto no cenário mundial quanto no nacional. O fim da ditadura e o Rock 
in Rio $^{6}$, também em 1985, traziam à tona a força da mobilização da juventude, tornando mais frequentes nas revistas assuntos relacionados a essa faixa etária. A juventude, após a ditadura militar, participava até mesmo da política, pois, a partir da Constituição de 1988, o voto foi tornado facultativo para quem tivesse entre $16 \mathrm{e}$ 18 anos de idade e, em 1992, o movimento dos cara pintada $^{7}$, composto majoritariamente por jovens, tomou conta das ruas.

Um exemplo da interferência do contexto da escolha da profissão fica explícito na reportagem "A difícil aposta da profissão" da IstoÉ :

Existe ainda uma área cujo desenvolvimento depende de uma importante condicional - se a abertura politica persistir, se o regime democrático florescer nesta década de 80. Então, um amplo campo estará aberto para o que se poderia chamar de "as profissões da democracia". [...] Democracia, não se duvide, também dá emprego. Essa é outra das esperanças para os anos 80 (Istó́, $\mathrm{n}^{\circ} 232$ p. 54,3 jun. 1981).

Segundo a maior parte das reportagens analisadas sobre vestibular, constata-se que é, a partir da profissão, que essa juventude vai definir sua autonomia e sua independência, ou seja, é um momento de definição de vida para os jovens. Isso fica visível em trechos como: “A aposta é importante demais. Não pode ser perdida. Para um jovem, o momento de escolher um diploma universitário é um lance de definição de sua vida." (IstoÉ, no 232, 3 jun.1981, p. 48). Essa discussão remete à noção de juventude como fase da vida preparatória da vida adulta.
As reportagens da década de 1980 e 1990 têm em comum uma frequente preocupação com o que futuro reserva aos jovens. A juventude carrega consigo uma série de expectativas por conta do caráter transitório da faixa etária, uma vez que "o presente não é apenas uma ponte entre o passado e o futuro, mas a dimensão que “prepara" para o futuro" (LECCARDI, 2005, p. 35). Quando a juventude é representada nas fontes analisadas, a preocupação com o futuro, tanto coletivo quanto individual, é frequente. No trecho seguinte da reportagem intitulada "Vestibular sem fantasias" (IstoÉ, $\mathrm{n}^{\mathrm{o}}$ 1002, 30 nov. 1988), a premissa anterior fica explicitada a partir do ponto de vista de uma candidata relativamente aos vestibulares do ano:

Somos uma geração de dúvidas. O futuro, para nós, é um filmezinho trágico onde 'nada do que sonhamos se realiza', diz a candidata Ariadne. 'Temos pressa de fazer tudo antes que o mundo acabe [...]' Segundo ela, por isso, é tão difícil escolher quando chega o vestibular (IstoÉ, $\mathrm{n}^{\circ} 1002,30$ jun. 1988, p. 57).

$\mathrm{Na}$ perspectiva do historiador alemão Reinhart Koselleck (2014), os jovens, por conta de seu espaço de experiência menor que o de indivíduos adultos, têm um horizonte de expectativa maior; o futuro - horizonte de expectativas - é muito mais amplo na juventude, uma vez que os jovens, biologicamente, ainda têm um longo período de vida e de construção de espaços de experiência. Os jovens têm um horizonte de expectativas muito maior em relação às gerações anteriores, já que “expectativas baseadas em experiências não surpreendem quando acontecem. Só pode surpreender aquilo que não é esperado" (KOSELLECK, 2006, p. 313). O

\footnotetext{
${ }^{6} \mathrm{O}$ Rock in Rio foi o primeiro evento de um dos maiores festivais de rock do mundo. O Festival durou 10 dias com um total de 1 milhão e 380 mil espectadores, o maior número de pessoas pagantes em um festival de música até então, com grande parte do público sendo jovem (IstoÉ, $\mathrm{n}^{\circ} 422,23$ jan. 1985 , p. 46).

${ }^{7}$ Em 1989, Fernando Collor de Mello foi eleito presidente do Brasil; quando assumiu a presidência em 1990, o custo de vida aumentou 1.430\%. Em 1992 ocorre o movimento que ficou conhecido com "Caras pintadas", que contribuiu para a instauração do processo de impeachment do presidente Collor e que teve uma grande participação juvenil. Ver mais em: DIAS, Luiz Antonio. Política e Participação Juvenil: os "caras-pintadas" e o movimento pelo impeachment. Revista História Agora: a revista do tempo presente ed, n. 4, 2008. Disponível em: <http://www.janduarte.com.br/textos/brasil/ caras_pintadas.pdf> Acesso em: 29 abr. 2018.
} 
caráter transicional da juventude garante que sua passagem será marcada por uma série de surpresas não previstas pelo longo horizonte de expectativas dos jovens.

Para os sociólogos Mario Margulis e Marcelo Urresti (1996), eles, além de uma moratória social, uma vez que este período é entendido como um período de preparação para o futuro, também possuem o que se chama de moratória vital, que é constituída pelo tempo de vida que todos, independentemente de classe social, gênero e etnia, possuem em relação aos adultos, o que significa um excedente temporal, funcionando como promessa de que o futuro é constituído de possibilidades que ainda se encontram em aberto.

$\mathrm{O}$ artigo intitulado "A difícil aposta da profissão", com o subtítulo "Escolher bem hoje para não ser o desempregado de amanhã", publicado na edição de número 232 da revista $I s t o E ́$, trazia afirmações de especialistas sobre o mercado de trabalho que aguardava os jovens. Os pesquisadores revelam que a juventude que pretendia ingressar em universidades por meio do vestibular iria ter pela frente uma série de interrogações; "Escaldados por surpresas [...], os especialistas em mercado de mão-de-obra [...] gostam de formular, em termos de futuro, algumas advertências gerais. A primeira delas: levar em conta que uma profissão pode estar bem hoje e mal em 1985, ou vice-versa" (IstoÉ, 3 jun. 1981, p. 48). A escolha da profissão certa, que trará retorno financeiro, a seleção de um curso com nítidas potencialidades para o futuro, a desvalorização do diploma perante a maior quantidade de formados e as consequências da abertura política para o mercado de trabalho eram os questionamentos centrais do artigo publicado em 3 de junho de 1981.

Mesmo com o aumento da concorrência, que dificultava ou impossibilitava a entrada dos jovens nas universidades, a conclusão de um curso de nível superior para a classe média ${ }^{8}$ brasileira e a obtenção de um diploma constituíam um importante passo para a estabilidade financeira, e também como marcador de distinção social. "Contudo, a classe média continua - provavelmente com razão - convencida de que a instrução superior é indispensável para o progresso social - e até para a sua sobrevivência" (IstoÉ, no 232, 3 jun. 1981, p. 48). Manter o status de detentora do conhecimento era imprescindível para essa classe média - frequentadora das melhores e mais tradicionais universidades brasileiras -, o público consumidor dessas revistas.

As incertezas que afetavam o futuro dos jovens que pretendiam entrar nas universidades não passavam, muitas vezes, de preocupações latentes. No trecho abaixo, fica visível que os próprios especialistas recomendavam que questões meritocráticas fossem deixadas de lado e que o jovem se aproveitasse de uma espécie de "currículo oculto" proporcionado por interferências familiares:

\begin{abstract}
Os especialistas ainda têm um último conselho a oferecer aos futuros candidatos ao mercado de trabalho - tirar toda vantagem possivel do que psicólogos americanos chamam de "currículo oculto". Trata-se da soma de influências familiares e ambientais que enriquecem a inteligência de uma criança e de um jovem, tornando-o, mais do que outros, apto para certas carreiras. Assim, o filho de um advogado bem-sucedido terá excelente probabilidade de dar-se bem na
\end{abstract}

\footnotetext{
${ }^{8}$ A classe média pode ser definida de acordo com várias classificações. O Instituto Brasileiro de Geografia e Estatística (IBGE) faz levantamentos sobre a renda das famílias, mas evitava compartimentá-las em classes. Uma classe média, segundo dados do IBGE de 2008, equivaleria a aproximadamente metade das famílias que se situavam em uma faixa de renda média (entre 2 e 10 salários mínimos por mês). Ver mais em: SCALON, Celi; SALATA, André. Uma nova classe média no Brasil da última década?: o debate a partir da perspectiva sociológica. Soc. estado., Brasília , v. 27, n. 2, p. 387407, Aug. 2012. Disponível em: $<$ http://www.scielo.br/scielo.php?script=sci arttext\&pid=S0102-69922012000200009> Acesso em: 27 abr. 2018.
} 
carreira do pai. [...] Em suma, é o velho elitismo em funcionamento - do quanto mais cedo melhor - que, depois, da etapa do vestibular, continuará se manifestando na época da formatura, na colocação no mercado de trabalho e pela vida afora (IstoÉ, n. 232, 3 jun. 1981, p. 50 e 51).

Apesar da ideia de um emprego garantido pelas relações familiares, uma espécie de ceticismo ia surgindo entre os jovens que constituíam o tema e, ao mesmo tempo, eram os entrevistados para a elaboração das reportagens, pois o Brasil se encontrava em um momento bastante instável, marcado por uma série de inseguranças, tanto políticas quanto econômicas. Algumas das reportagens faziam críticas ao sistema educacional brasileiro e às motivações da juventude representada nas reportagens, que buscava a aprovação nos vestibulares, como no trecho a seguir: "Há quem lamente, sobretudo, que o estudante tenha perdido, em algum ponto entre a alfabetização e o exame vestibular, a noção de por que deve estudar" (Veja, 4 fev. 1987, p. 39). Apesar de se admitir que o sistema de seleção era falho e deficitário, ainda recaía sobre os jovens a responsabilidade de perder a noção do que os motivava a estudar.

Numa entrevista com João Carlos Di Genio, o criador do curso pré-vestibular Objetivo ${ }^{9}$, na seção páginas amarelas da revista Veja, faz uma série de afirmações sobre os problemas do sistema educacional brasileiro. Segundo a entrevista intitulada "O vestibular é injusto", para o entrevistado, "a evasão escolar já é uma triagem" (Veja, 27 jan. 1982, p. 3) uma vez que "menos de $10 \%$ dos que começaram a escola terminaram o segundo grau" (Veja, 27 jan. 1982, p. 3).
Na reportagem "Eu sou normal”, na edição número 1408 da revista $I s t o E ́$, essa triagem anteriormente exposta fica visível, uma vez que "Apenas três [dos aprovados em primeiro lugar em vestibulares de universidades públicas] fizeram escola pública, o que comprova a idéia de que a entrada em uma boa universidade é também a consequência de uma vida escolar produtiva e de qualidade" (IstoÉ, 25 set. 1996, p. 47). Ou seja, quem era aprovado nos vestibulares vinha, majoritariamente, de uma formação em escolas particulares.

A reportagem da $I s t o E$, intitulada "Os céticos de 82 - Nos vestibulares desse ano, uma juventude sem ilusões", salienta que entre os jovens pesquisados havia uma descrença no futuro naquele ano: “As razões dessa desilusão são conhecidas. Os vestibulandos puderam acompanhar $[. .$.$] as intensas lamentações de seus ante-$ cessores nos bancos universitários, os quais, formados, não encontraram emprego" (IstoÉ, no 264, 13 jan. 1982, p. 38). O diploma universitário ia deixando de ser uma garantia de uma vida financeira confortável para os padrões da classe média brasileira. A quantidade de vagas nas universidades públicas não acompanhava a demanda, como na ideia expressa no seguinte trecho da mesma reportagem: "No Brasil, a pressão da juventude sobre as escassas vagas no ensino superior não dá sinal, ainda, de diminuir de modo importante" (IstoÉ, n $^{\circ} 264$, 13 jan. 1982, p. 39).

A crise econômica que assolava o Brasil em meados dos anos 1980, somada à aparente desvalorização do diploma de curso superior no mercado de trabalho, tornava a juventude cética a respeito de seu futuro profissional. Mesmo tendo como cenário um contexto des-

${ }^{9}$ Em 1965, os estudantes de Medicina João Carlos Di Genio e Dráuzio Varella e os médicos Roger Patti e Tadasi Itto fundaram um pequeno curso preparatório para as faculdades de Medicina na região central da cidade de São Paulo. O sucesso alcançado nos exames daquele ano pelos alunos por eles preparados fez com que, em 1966, o Curso Objetivo fosse um dos maiores da cidade. Em 1970, foi criado o Colégio Objetivo, com currículo de Ensino Médio. Em 1972, foram implantadas as Faculdades Objetivo, embrião da futura Universidade Paulista - UNIP. Hoje, a instituição abrange o ciclo completo do sistema educacional brasileiro, da educação infantil à pós-graduação universitária. Informações retiradas do site da instituição. In: CURSO OBJETIVO VESTIBULARES. Histórico, c1997-2018. Disponível em: < http://www.curso-objetivo.br/curso/historico.aspx > Acesso em: 28 abr. 2018. 
favorável, a juventude brasileira ainda era sinônimo de prosperidade e expectativas: "Os candidatos nos vestibulares aumentaram [...] E essa tendência parece demonstrar que existe pelo menos uma vertente de otimismo e esperança nesta cética geração de 1982 - apesar das desilusões, [...] e do medo ao desemprego futuro" (IstoÉ, no 264, 13 jan. 1982, p. 39).

É a partir da crescente desilusão com os cursos tradicionais - que supostamente garantiriam emprego e com o momento de pré-redemocratização do país, que carreiras antes desvalorizadas começam a se tornar alvo da juventude. "O desamor dos vestibulandos de 1982 pelas áreas técnicas estendeu-se praticamente por todas as universidades" (IstoÉ, no 264, 13 jan. 1982, p. 39) e "cursos de humanidades" - como direito, principalmente, história, pedagogia e psicologia - surpreendem por seu significativo aumento nas listas de relação candidato/vaga dos vestibulares.

Em 1982 e 1983, começam a aparecer, em ambas as revistas, propagandas do curso pré-vestibular Anglo $^{10}$ - estabelecimento voltado à preparação de pessoas que pretendiam passar em vestibulares. As propagandas tinham em comum o discurso enaltecedor da figura do jovem como definidor de seu próprio futuro e também dialogavam diretamente com o leitor, como é visível no trecho a seguir: "É cada vez mais difícil conquistar um lugar no mundo e, quanto mais cedo você tomar consciência disso, melhor será para você e para toda a sociedade" (Veja, no 751, 26 jan. 1983, p. 41).

Em 1988, na reportagem "Vestibular sem fantasias - Os jovens vão aos exames mas não têm ilusão com suas futuras profissões", publicada na edição de número 1002 da IstoÉ, uma visível perda de interesse pelas ciências humanas - antes em ascensão - estava relacionada ao ensino da época, que passava por momentos de greves e baixos salários. As tradicionais carreiras, como a medicina e as engenharias, também deixaram de ser o alvo de interesse dos jovens de classe média, pois, segundo a reportagem, tais carreiras haviam deixado de dar o retorno financeiro esperado. Novas carreiras que ascendiam a partir do momento que o país vivia eram favoritas, da mesma forma que cursos que prezavam pela interdisciplinaridade, uma vez que os alunos tinham "mais consciência das limitações do mercado", e sabiam que, muitas vezes, o diploma universitário só era "uma porta para o desemprego" (IstoÉ, no 1002,30 nov. 1988, p. 57).

No seguinte trecho, a perspectiva anterior fica visível: "Como o movimento estudantil, que no passado fez inchar os cursos de Filosofia e Sociologia e Política é coisa do passado, também ficou para trás a corrida pelas áreas nobres: Medicina e Engenharia. Estas duas carreiras não são mais minas de dinheiro" (IstoÉ, $\mathrm{n}^{\circ}$ 1002, 30 jun.1988, p. 57). As carreiras consideradas mais tradicionais, como as citadas anteriormente, dão lugar às aspirações individuais dos jovens representados nas revistas:

Por isso, os próprios cursinhos que fazem um preparo de massa para os vestibulares - o Objetivo colabora com 70 mil dos 95 mil candidatos à Fuvest - preocupam-se em orientar os seus alunos para carreiras que respondam mais às suas aptidões individuais que à expectativa de ascensão econômica (IstoÉ, $\mathrm{n}^{\circ} 1002,30$ jun. 1988, p. 57).

\footnotetext{
${ }^{10} \mathrm{O}$ anglo surgiu após a criação, em 1894, do Ginásio Professor Guerreiro, renomeado, depois da Primeira Guerra Mundial, Ginásio Anglo-Latino, em homenagem aos aliados. No final dos anos 30, os herdeiros venderam as instalações para professores, que expandiram o ginásio e abriram o Colégio Anglo-Latino. Na década seguinte, o Anglo-Latino firmou-se como o melhor colégio particular de São Paulo e o melhor curso preparatório para Exatas. Até então, o Anglo é um curso pré- vestibular paulista com altos índices de aprovação nas universidades mais concorridas do Brasil. ANGLO VESTI-

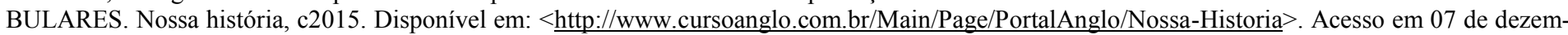
bro de 2018.
} 
$\mathrm{Na}$ década de 1990, tem-se uma melhor noção do mercado de trabalho, inaugurado pelas mudanças políticas e econômicas após o retorno à democracia. A virada na escolha dos jovens nos vestibulares, aumentando a procura por cursos antes pouco conhecidos e cursados, deveu-se, segundo as reportagens, à noção de que a expectativa de retorno financeiro podia não se concretizar com as profissões ditas tradicionais. Isso, aparentemente, fez com que os jovens optassem por cursos que traziam satisfação pessoal. Na reportagem da $I s t o E$ de 1998, carreiras como turismo e artes emergem nos vestibulares; “embora práticos, os jovens estão investindo mais em seus sonhos. [...] A busca do prazer no trabalho é cada vez mais presente e contribui para que as artes, antes tidas como atividades paralelas, seja transformada em carreira" (IstoÉ, $\mathrm{n}^{\mathrm{o}}$ 1519, 11 nov. 1998, p. 86).

A preferência pelos cursos tradicionais ainda era frequente, sendo que "Um em cada três vestibulandos ainda prefere Medicina, Direito ou Engenharia" (IstoÉ, no 1519, 11 nov. 1998, p. 86), no entanto, “a migração da área de exatas para a de humanas "é uma realidade da década de 90", constata José Atílio Vanin, coordenador da Fuvest" (IstoÉ, no 1519, 11 nov. 1998, p. 86).

O futuro, mais uma vez, aparece como tema recorrente nas reportagens dos anos 1990. Profissões que seriam sucesso no futuro são a principal aposta dos jovens que prestam vestibular e suas escolhas são pautadas na análise das carreiras que podem vir a fazer sucesso e garantir um emprego. $\mathrm{O}$ excerto seguinte da reportagem "Ser ou não ser" resume bem a premissa anterior: "Como definir-se por uma profissão no momento em que o país passa por uma profunda crise? [...] Pior: como tomar uma decisão acertada [...] num mundo marcado por rápidas mudanças de valores e conceitos? (IstoÉ, no 1303, 21 set. 1994, p. 63).
A necessidade de profissionais com uma formação ampla era uma demanda frequente nas reportagens, uma vez que se tinha uma noção de que "não há receita para uma escolha acertada" (IstoÉ, $\mathrm{n}^{\circ}$ 1303, 21 set. 1994, p. 63). O sucesso no futuro profissional dos jovens representados nas revistas seria garantido pela capacidade de adaptação ao mercado; "Acabou a era da ultra-especialização. O futuro pertence àqueles que souberem combinar conhecimento específico com uma ampla e sólida formação generalista" (IstoÉ, no 1303, 21 set. 1994, p. 63).

\section{Algumas considerações}

A juventude representada nas revistas tem como característica, no que diz respeito à escolha dos cursos de graduação, uma noção bastante complexa e diversificada de áreas de atuação. A ascensão e queda da popularidade de alguns cursos, como em casos explicitados nas reportagens, demonstram a atenção dessa parcela de jovens em relação ao contexto do país e à possibilidade de inserção no mercado de trabalho após a conclusão da graduação escolhida.

Os artigos das revistas são produzidos por jornalistas (normalmente adultos mais velhos e, profissionalmente, estabelecidos), por sua vez subalternos às suas editoras, que buscam um público específico, que é o da classe média branca e letrada das metrópoles brasileiras. Quando os jovens aparecem nas páginas das publicações semanais, eles quase sempre são representações uniformes, a partir do ponto de vista dos repórteres, de uma juventude que faz parte da classe média - o público alvo das revistas. Sua entrada nas universidades públicas brasileiras por meio do vestibular, de acordo com as fontes analisadas, significava, praticamente, a manutenção de privilégios das classes abastadas dos centros urbanos brasileiros, uma vez que apenas uma 
pequena parcela da população jovem brasileira concluía o segundo grau.

No âmbito nacional, e partindo de um pressuposto sociológico, é no fim dos anos 1990 que "estudos voltados para a consideração dos próprios jovens e suas experiências, suas percepções, formas de sociabilidade e atuação" (ABRAMO, 1997, p. 25) passam a ser produzidos em maior escala. A tematização da juventude está, muitas vezes, intrinsecamente ligada a uma relação que caracteriza os jovens como problema ou como alvo de campanhas publicitárias, divisões pautadas principalmente em recortes de classe. A juventude que aparece nas revistas Veja e IstoÉ, dentro dos artigos selecionados, é sempre uma juventude branca, de classe média, e que habita os grandes centros urbanos brasileiros, extremamente privilegiada por seu status econômico.

\section{Referências}

AARÃO REIS, Daniel (Coord.). Modernização, Ditadura e Democracia: 1964-2010 - V. 5. Rio de Janeiro: Objetiva, 2014.

ABRAMO, Helena Wendel. "Considerações sobre a tematização social da juventude no Brasil". Revista Brasileira de Educação, São Paulo: ANPED/PUC-SP, n. 5 e 6, p. 25-36, 1997. Número especial: Juventude e Contemporaneidade.

ABREU, Alzira Alves de. A modernização da Imprensa (1970 - 2000). Rio de Janeiro: Jorge Zahar Ed., 2002.

CAPELATO, Maria Helena. Imprensa e História do Brasil. São Paulo: Contexto/EDUSP, 1988.

CARVALHO, F. O conceito de representações coletivas segundo Roger Chartier. Diálogos, América do Norte, 9 mai. 2010. Disponível em: <http://www.dialogos.uem.br/index.php?journal=ojs\&page=article\&op=view\&path\% 5B $\% 5 \mathrm{D}=170>$ Acesso em: 26 abr. 2018.

CHARTIER, Roger. O mundo como representação. Estudos Avançados. v.5, n.11, São Paulo, jan./abr. 1991.

. Defesa e ilustração da noção de representação. Fronteiras, Dourados, MS, v. 13, n. 24, p. 15-29, jul./dez. 2011.

GERZSON, Vera Regina Serezer. A mídia como dispositivo da governamentalidade neoliberal: os discursos sobre educação nas revistas Veja, Época e Istoé. 2007. Tese (Doutorado) - Universidade Federal do Rio Grande do Sul. Porto Alegre, 2007.

KLEIN, Herbert S.; LUNA, Francisco Vidal. População e sociedade. In: REIS, Daniel Aarão. Modernização, ditadura e democracia (1964-2010). Rio de Janeiro: Objetiva, 2014. p. 31-73.

KOSELLECK, Reinhart. Futuro Passado: contribuição à semântica dos tempos históricos. Rio de Janeiro: Contraponto. Ed. PUC-Rio, 2006, p. 233-246.

KOSELLECK, Reinhart. Estratos do tempo: estudos sobre história. Rio de Janeiro: Contraponto. Ed. PUC-Rio, 2014.

LECCARDI, Carmen. Para um novo significado do futuro: mudança social, jovens e tempo. Tempo Social, São Paulo, v. 17, n. 2, p. 35-57, nov. 2005. Disponível em: <https://www.revistas.usp.br/ts/article/view/12470/14247> Acesso em: 25 abr. 2018. 
LEVI, Giovanni; SCHMITT, Jean-Claude. História dos Jovens 1 - Da Antiguidade à Era Moderna. São Paulo: Schwarcz LTDA, 2006.

LOHN, Reinaldo Lindolfo. (Org.). História nas bancas de revistas: um país impresso - entre representações sociais e culturas políticas. Ponta Grossa: TodaPalavra, 2016. p. 191-211.

MARGULIS, Mario; URRESTI, Marcelo. La juventud es más que una palabra. In: Margulis, M. (Org.). La juventud es más que una palabra. Buenos Aires, Biblos, 1996. p. 19-32.

MIRA, Maria Celeste. O leitor e a banca de revistas: o caso da editora Abril. 1997. Tese (Doutorado) - Programa de Pós-graduação em Sociologia, Unicamp - Campinas, 1997.

RIBEIRO, Ana Paula Goulart. Modernização e concentração: a imprensa carioca nos anos 1950-1970. In: NEVES, Lúcia Maria B. P. et alii (Orgs.). História e imprensa: representações culturais e práticas de poder. RJ: DP\&A; FAPERJ, 2006.

SILVA, Cristiani Bereta da. A invenção do futuro do Brasil: usos políticos do passado na Veja (1968-1978). In: AREND, Silvia Maria Fávero (Org.). Um país impresso: história do tempo presente e revistas semanais no Brasil (1960-1980). Curitiba: CRV, 2014. p. 21-42.

SILVA, Juliana Miranda da. Democracia, cidadania e construção de direitos nas narrativas das Revistas Veja e Isto é (1974-1988). 211 p. Dissertação (Mestrado) - Universidade do Estado de Santa Catarina, Centro de Ciências Humanas e da Educação, Mestrado em História, Florianópolis, 2014.

Submissão: $30 / 04 / 2018$ Aceite: $10 / 12 / 2018$ 